\title{
Occurrence of Pregnancies among HIV Infected Indian Women: Does Knowledge about HIV Status Make a Difference?
}

\author{
Shrinivas Darak, ${ }^{1,2}$ Inge Hutter, ${ }^{1}$ Sanjeevani Kulkarni, ${ }^{2}$ \\ Vinay Kulkarni, ${ }^{2}$ and Fanny Janssen ${ }^{1,3}$ \\ ${ }^{1}$ Population Research Centre, Faculty of Spatial Sciences, University of Groningen, 9747 AD Groningen, Netherlands \\ ${ }^{2}$ Prayas Health Group, Amrita Clinic, Pune, Maharashtra 411004, India \\ ${ }^{3}$ The Netherlands Interdisciplinary Demographic Institute, Lange Houtstraat 19, 2511 CV The Hague, Netherlands \\ Correspondence should be addressed to Shrinivas Darak; shirishdarak@gmail.com
}

Received 10 September 2014; Revised 12 February 2015; Accepted 16 February 2015

Academic Editor: Jonathan Haughton

Copyright (C) 2015 Shrinivas Darak et al. This is an open access article distributed under the Creative Commons Attribution License, which permits unrestricted use, distribution, and reproduction in any medium, provided the original work is properly cited.

\begin{abstract}
This is the first study to examine the behavioural effect of HIV on fertility among HIV infected women in India. Retrospective calendar data from ever-married HIV infected women between 15 and 45 years of age, attending a specialized HIV clinic in Pune, Western India $(N=560)$, were analysed. Directly standardized overall and parity-specific pregnancy rates were compared among HIV infected women before and after coming to know about their HIV status. The age- and parity-standardized pregnancy rates and age-standardized parity-specific pregnancy rates were statistically significantly lower after knowing about HIV status as compared to before the HIV status was known. Analysis of parity-specific rates suggested lower likelihood of HIV infected women to progress to higher parity. The clear behavioural impact of HIV on fertility observed should be taken into account while estimating HIV infected pregnant women in the country. Ensuring access to information and services for PMTCT to HIV infected couples is essential to support informed reproductive decision making among them.
\end{abstract}

\section{Introduction}

While high income countries have long maintained near universal coverage of antiretroviral treatment (ART) for pregnant women, the coverage of effective ART has also reached $68 \%$ for pregnant women in low and middle income countries in 2013 [1]. With recently launched global targets at the United Nations General Assembly, efforts would be made to diagnose $90 \%$ of all people living with HIV, treat $90 \%$ of all diagnosed people, and achieve viral suppression in $90 \%$ of all the people treated for HIV by 2020 [2]. Increased access to ART and to prevention of mother to child transmission of HIV (PMTCT) services has been hypothesized as one of the important determinants of fertility desires and behaviours $[3,4]$.

The relation between HIV infection and fertility is far from being straightforward. Most previous studies on the effect of HIV on pregnancy rates, conducted prior to widespread availability of antiretroviral treatment (ART), suggest reduced fertility due to HIV at population level $[5,6]$ and individual level [7] with an exception of a few studies that did not find any association between HIV infection and reduction in pregnancy rates [8].

There is emerging literature on fertility among HIV infected women who have access to ART. The comparison of the literature on effect of HIV on fertility from preART and post-ART era yields ambiguous results. While the population level studies in the pre-ART era suggested decline in fertility due to HIV $[5,6,9]$ as a result of advanced HIV disease on lowering fecundity, increasing mortality, and reduced interest or opportunities for sexual activity, a few studies also suggest that HIV may increase fertility due to reduced period of breastfeeding and desire for more children due to increased child mortality [10]. More recent studies from post-ART era showed an increase in pregnancy rate among women initiating or receiving ART [11, 12] due to restoration of fertility and sexual activity [13]. However there are also studies that reported lower pregnancy rates 
among HIV infected women on ART despite its beneficial effect on survival and for PMTCT [14]. There is growing research suggesting that ART might increase pregnancy desire and intention but may not increase actual incidence of pregnancies $[4,15]$ and the majority of the pregnancies in women on ART might be unplanned pregnancies [16-18] due to lack to effective contraception.

HIV can have biological as well as behavioural effects on reproduction among HIV infected couples. The biological effect would be the effect of the virus and the disease progression on fecundity $[19,20]$, that is, the physical ability of the woman to become pregnant and her ability to continue pregnancy to term. The behavioural effect is exerted through the alteration in reproductive decision making of infected couples after they become aware about their HIV status [19]. Many studies have assessed the biological and behavioural effects together [21, 22]. Most of these studies showed a decline in pregnancy rates among HIV infected women. However, it remains unclear if this decline is due to the biological effect or behavioural factors [14]. While it is being acknowledged that the factors predictive of pregnancy among women not aware of their HIV status may differ from those who are aware about their status $[8,14,23]$, there is lack of research on the differential effect of HIV on fertility behaviour taking the knowledge of HIV status of the woman and/or her partner into account.

The objective of this paper is to assess the behavioural impact of HIV on fertility, more specifically to determine the differences in pregnancy rates among HIV infected women from Maharashtra, Western India, before and after knowing about their HIV status. In India, the number of centres providing HIV counselling and testing services to pregnant women almost doubled from 6480 centres in the year 200910 to 12897 centres in 2012-13 [24]. As a result 63\% of the estimated pregnant women in India were counselled and tested for HIV by December 2012 [24]. With increasing proportion of women knowing about their HIV status early in their reproductive career, understanding the effect of knowledge about HIV status on fertility becomes important for providing reproductive care to HIV infected women.

\section{Materials and Methods}

2.1. Setting. The study was conducted among HIV infected women attending a specialized HIV clinic in Pune, Maharashtra, Western India. The clinic is run by a not-for-profit organization Prayas. All HIV infected women who attended the clinic from November 2010 to December $2011(N=1023)$ were screened for eligibility. Ever-married HIV infected women aged 15-45 and who knew about their HIV status for more than 6 months were considered eligible for the study and were informed about it $(N=811)$.

2.2. Data Collection. After written informed consent, data were collected by woman interviewers by means of reproductive event history calendar and structured questionnaires from 622 women who participated in the study. Retrospective data on the reproductive events of the woman such as the number and outcome of pregnancies, use of temporary and permanent contraception, and cohabitation with husband were collected in an event history calendar along with information on HIV related factors such as timing and reasons for HIV diagnosis, disclosure of HIV status, and husband's HIV status. Detailed information about each pregnancy that occurred after the woman was diagnosed as HIV infected and information on fertility desires and contraceptive use among women who were married and fecund at the time of interview were collected through structured questionnaires and were linked to sociodemographic information collected at the time of interview such as age, education, socioeconomic status, parity, and place of residence. In addition, data were collected on last menstrual period, month and year of hysterectomy, and month and year of female sterilization among women who opted for it.

Data were entered in a specially designed software using MS Access as a backend and Visual Basic (VB) as a user interface. Ten percent of the random sample of the data was double entered to check for data entry errors. A software program was written in VB to export data in MS Excel for further analysis.

2.3. Observation Period and Final Sample. We retrospectively collected information in 2010-2011 on reproductive events backwards from the date of interview till 15 years of age of the women. To account for the change in fertility that occurred over time we had to decide on a starting year of the observation, and because prior to 1994 only three women had pregnancies after knowing about their HIV, we choose 1994 as the start of our observation period. We choose 2009 as the final year of our observation period as there was overrepresentation of women referred into the PMTCT program in the last two years.

By setting the observation period to 1994 up to 2009, the final sample included $569 \mathrm{HIV}$ infected ever-married women. The profile of the women in the final sample is shown in Table 1 . The average age of the women at the time of interview was 32.6 years with the mean parity of 1.5 children. The average follow-up period (from registration to the clinic till date of interview) was 3.4 years.

2.4. Outcome Measures. To estimate the age- and parityspecific pregnancy rates, the observation period was clubbed into four-year periods (1994-1997, 1998-2001, 2002-2005, and 2006-2009) because of small numbers. The age- and parity-specific pregnancy rates were calculated by dividing the number of age- and parity-specific pregnancies in the four-year period by the age- and parity-specific number of person years during which the women were at risk of having a pregnancy in the same four-year period.

Women were considered to be at risk of having a pregnancy from the start of their first marriage until the marriage is dissolved due to widowhood or divorce or if the woman or her partner had opted for a permanent method of contraception such as tubal ligation or vasectomy, respectively. The observations were censored from the time women (1) 
TABLE 1: Profile of HIV infected ever-married Indian women in the study (1994-2009) $(N=569)$.

\begin{tabular}{|c|c|c|c|c|}
\hline & Variable & Category & $N$ & $\%$ \\
\hline \multirow{28}{*}{$\begin{array}{l}\text { Demographic } \\
\text { factors }\end{array}$} & \multirow{4}{*}{ Age } & $20-24$ & 42 & 7.4 \\
\hline & & $25-29$ & 117 & 20.6 \\
\hline & & $30-34$ & 192 & 33.7 \\
\hline & & $35-39$ & 162 & 28.5 \\
\hline & \multirow{5}{*}{ Education } & $\geq 40$ & 56 & 9.8 \\
\hline & & No schooling & 50 & 8.8 \\
\hline & & $\begin{array}{l}\text { Primary } \\
(1-7 \text { yrs })\end{array}$ & 126 & 22.1 \\
\hline & & $\begin{array}{l}\text { Secondary } \\
\text { (8-12 yrs) }\end{array}$ & 256 & 45.0 \\
\hline & & Higher ( $\geq 13$ yrs) & 137 & 24.1 \\
\hline & \multirow{4}{*}{$\begin{array}{l}\text { Socioeconomic } \\
\text { class }\end{array}$} & Upper middle & 20 & 3.5 \\
\hline & & Lower middle & 298 & 52.4 \\
\hline & & Upper lower & 235 & 41.3 \\
\hline & & Lower & 16 & 2.8 \\
\hline & \multirow{4}{*}{$\begin{array}{l}\text { Marital status at } \\
\text { interview }\end{array}$} & $\begin{array}{l}\text { Living as } \\
\text { married }\end{array}$ & 345 & 64.6 \\
\hline & & Divorced & 5 & 0.9 \\
\hline & & Widowed & 207 & 36.4 \\
\hline & & Separated & 12 & 2.1 \\
\hline & \multirow{3}{*}{ Parity } & 0 & 70 & 12.3 \\
\hline & & 1 & 236 & 41.5 \\
\hline & & $2+$ & 263 & 46.2 \\
\hline & \multirow{3}{*}{ Death of a child } & Yes & 87 & 15.3 \\
\hline & & No & 423 & 74.3 \\
\hline & & Not applicable & 59 & 10.4 \\
\hline & \multirow{5}{*}{$\begin{array}{l}\text { Ever use of } \\
\text { contraception }\end{array}$} & $\begin{array}{l}\text { Female } \\
\text { sterilization }\end{array}$ & 198 & 34.8 \\
\hline & & Condom & 426 & 74.9 \\
\hline & & Pill & 107 & 18.8 \\
\hline & & IUD & 112 & 19.7 \\
\hline & & Emergency pills & 15 & 2.6 \\
\hline \multirow{7}{*}{$\begin{array}{l}\text { HIV related } \\
\text { factors }\end{array}$} & \multirow{4}{*}{$\begin{array}{l}\text { Reason of HIV } \\
\text { diagnosis }\end{array}$} & During ANC & 185 & 32.5 \\
\hline & & $\begin{array}{l}\text { Husband tested } \\
\text { positive }\end{array}$ & 199 & 35.0 \\
\hline & & Illness & 118 & 20.7 \\
\hline & & Other & 67 & 11.8 \\
\hline & \multirow{3}{*}{$\begin{array}{l}\text { Husband's HIV } \\
\text { status }\end{array}$} & Infected & 464 & 81.5 \\
\hline & & Uninfected & 42 & 7.4 \\
\hline & & $\begin{array}{l}\text { Not } \\
\text { tested/unknown }\end{array}$ & 63 & 11.1 \\
\hline
\end{tabular}

were menopausal, (2) had hysterectomy, (3) had opted for sterilization, and (4) were pregnant.

2.4.1. Rates before and after Knowing about HIV Status. The entire period for which the women were at risk of having a pregnancy was then divided into a period before knowing about the couple's HIV positive status starting from marriage till anyone of the partners was aware about his/her HIV positive status and a period after knowing about the couple's $\mathrm{HIV}$ positive status starting from knowledge about HIV status among any one of the partners till the woman is no longer at risk of pregnancy. Dates of HIV testing of the woman and her partner were collected from the women. Of the total 569 women, $89 \%$ (506) of the women reported to know the timing of their husbands' HIV test and the test result. In 260 (51.4\%) cases, husband's HIV testing was prior to the women's and in 199 (39.3\%) cases husband's testing was after the woman's. In $47(9.3 \%)$ cases both the woman and her husband were tested on the same day. Disclosure of HIV positive status to the partner within a month of HIV testing was $76.5 \%$ when the husband was tested first and $81.4 \%$ when the woman was tested first. Due to high rates of immediate disclosure to the partner and assuming that fertility behaviour can get affected even if one partner is tested HIV positive and is aware of his/her HIV status, the period after knowing about HIV status was considered when any one of the partners is tested HIV positive and is aware about it.

2.5. Analytical Approach. To control for the effect of age, parity, and calendar time on fertility, direct standardization was used to estimate pregnancy rates before and after knowing about HIV. The age and parity distribution of women in the four-year period 2002-2005 was considered as the standard population and was applied to the age- and parity-specific pregnancy rates in the different four-year periods to obtain the age- and parity-standardized pregnancy rates.

Additionally, age-standardized parity-specific pregnancy rates were estimated by multiplying the age-specific rates by parity for the different four-year periods with the parityspecific age distribution of women in the standard population 2002-2005. The confidence intervals of the rates were estimated with the software OpenEpi which is free and open source software for epidemiologic statistics [25].

Ratios of the standardized rates were used to compare the standardized rates before and after knowing about HIV. Additionally, the confidence intervals of the rate ratios using the method described by Smith (1987) and presented in the book by Boyle and Parkin [26] were estimated to assess the statistical significance.

2.6. Ethical Consideration. The study protocol, consent forms, and data collection tools were reviewed and approved by an Independent Ethics Committee for Research (IECR) of Prayas. The ethics committee is registered with the government agency (registration number: ECR/146/Indt/MH/2014). Informed written consents were obtained from the women. The information collected during the interviews was kept confidential among the study team. Counselling support was available to women when required.

\section{Results}

3.1. Pregnancy Rates before and after Knowing about HIV. From 1994 to 2009, a total of 569 HIV infected ever-married women were at risk of pregnancy and had a total of 1037 
TABLE 2: Crude and age- and parity-standardized pregnancy rates among 569 HIV infected ever-married Indian women, before and after knowing about HIV status, 1994-2009.

\begin{tabular}{lcccc}
\hline & \multicolumn{2}{c}{$\begin{array}{c}\text { Crude pregnancy } \\
\text { rate/100 person years }\end{array}$} & $\begin{array}{c}\text { Age- and } \\
\text { parity-standardized } \\
\text { pregnancy rate/100 } \\
\text { person years } \\
\text { Rate }\end{array}$ & $\begin{array}{c}(95 \% \mathrm{CI}) \\
\text { Rate }\end{array}$ \\
& 29.63 & $(27.87-31.47)$ & 29.48 & $(28.00-30.95)$ \\
\hline $\begin{array}{l}\text { Total } \\
\begin{array}{l}\text { Before knowing } \\
\text { about HIV status }\end{array}\end{array}$ & 46.14 & $(43.10-49.28)$ & 45.15 & $(42.99-47.31)$ \\
$\begin{array}{l}\text { After knowing } \\
\text { about HIV status }\end{array}$ & 10.30 & $(8.81-11.96)$ & 10.40 & $(8.91-11.89)$ \\
\hline
\end{tabular}

pregnancies, resulting in a crude pregnancy rate of $29.63(95 \%$ CI 27.87-31.47). The overall age- and parity-standardized pregnancy rate $\left(\mathrm{SPR}^{\text {Total }}\right)$ was $29.48 / 100$ person years $(95 \% \mathrm{CI}$ 28.00-30.95) (Table 2).

Of the 569 women at risk, 560 women contributed to 1887.8 person years of observation before knowing about the couple's positive HIV status and had 871 pregnancies during this period (pregnancy rate $46.14 / 100$ person years) and 395 women contributed to 1612.1 person years of observation after knowing about the couple's HIV positive status and had 166 pregnancies during this period (pregnancy rate 10.30/100 person years). Nine women did not contribute to the period before knowing about HIV status as they were aware that their partners got diagnosed with HIV prior to marriage. The crude pregnancy rate after knowing about HIV positive status was much lower than the rate before knowing about HIV [rate ratio (RR) 0.22, (95\% confidence interval (CI) 0.190.26)] (Table 2). Also, after controlling for age, parity, and calendar time, the pregnancy rate after knowing about HIV status ( $\mathrm{SPR}^{\mathrm{After}}$ ) was much lower than the age- and paritystandardized pregnancy rate before knowing about HIV $\left(\mathrm{SPR}^{\text {Before}}\right)$ [RR 0.23 (95\% CI 0.21-0.26)]. The standardized pregnancy rates after knowing about HIV were $77 \%$ lower as compared to before knowing about HIV (Table 2).

3.2. Standardized Parity-Specific Pregnancy Rates before and after Knowing about HIV. The age-standardized parityspecific pregnancy rates are shown in Figure 1. For all the different parities, the age-standardized parity-specific rates after knowing about HIV $\left(\mathrm{SPR}_{\mathrm{P}}^{\mathrm{After}}\right)$ were significantly lower than the age-standardized parity-specific rates before knowing $\left(\mathrm{SPR}_{\mathrm{P}}^{\text {Before }}\right)\left[\mathrm{RR}_{\text {parity0 }}-0.46(95 \% \mathrm{CI} 0.39-0.54) ; \mathrm{RR}_{\text {parityl }}-0.20\right.$ (95\% CI 0.14-0.28); and $\mathrm{RR}_{\text {parity } 2+}-0.16$ (95\% CI 0.11-0.22)]. The drop in pregnancy rate from parity 0 to parity 1 was much higher after knowing about HIV (65\% decline) compared to before knowing (20\% decline). From parity 1 to parity 2 and over, the pregnancy rate declined by $48 \%$ after knowing about HIV compared to $35 \%$ before knowing about HIV.

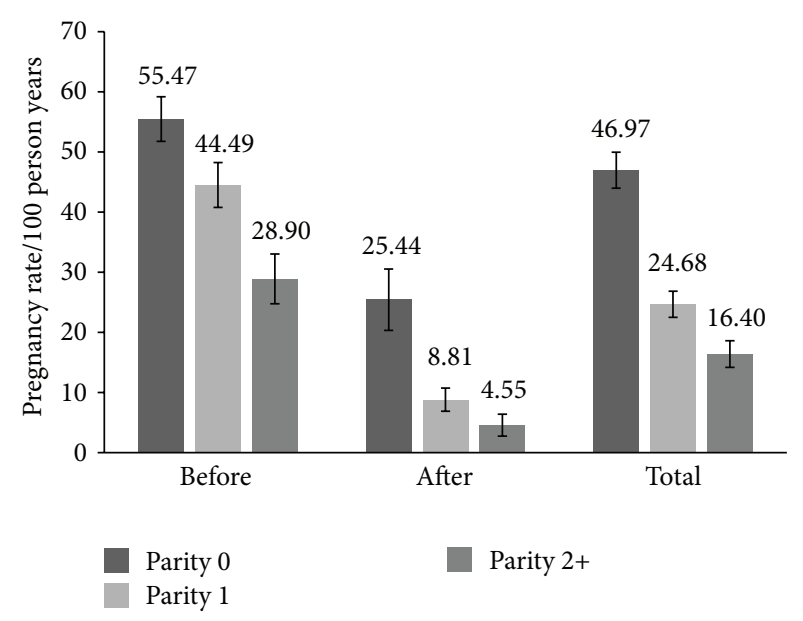

FIGURE 1: Age-standardized parity-specific pregnancy rates and 95\% confidence intervals before versus after knowing about HIV status among 569 HIV infected ever-married Indian women, 1994-2009.

\section{Discussion}

Our results suggest a significant behavioural impact of HIV infection on HIV infected women's fertility in Western India. The age- and parity-standardized pregnancy rates and agestandardized parity-specific pregnancy rates were statistically significantly lower among women after knowing about their HIV positive status compared to the pregnancy rate before knowing about their HIV status.

Several factors could lead to lower pregnancy rates after knowledge about HIV status. A qualitative study from India [27] among HIV infected women documented that the desire for motherhood and the decision to have a child were related to family support, especially when family members offered to take care of the child in the future in the event of parental death. Though HAART has instigated hope among HIV infected people and had contributed to reducing fear about death and uncertainty about the future, fear of transmitting HIV to the baby [28] could still be an important factor affecting the desired family size of HIV infected couples. Analysis of additional data from the interviews among HIV infected married and fecund women in this study $(N=229)$ showed that concern about transmitting HIV infection to the child (17\%), fear among women that having a child might affect their health (27\%), and potential financial constraints due to children (18\%) were reported as reasons for not desiring children.

The age-standardized parity-specific pregnancy rates after knowing about HIV were statistically significantly lower for all three parities compared to age-standardized parityspecific pregnancy rates before knowing about HIV. Within the parity-specific rates after knowing about HIV, the drop in pregnancy rate from parity 0 and parity 1 was significantly larger suggesting that couples diagnosed as HIV infected before the birth of their first child are likely to have only one child. It appears that couples with previous child/children are unlikely to have any further child/children after knowing about their HIV status. Not having any previous child has 
been identified as one of the only two significant predictors of fertility desires in a recent meta-analysis that included 20 studies across the world [29]. The other significant factor was age $<30$ years. ART was not significantly associated with fertility desire in that study. This clearly shows that the timing of HIV diagnosis with respect to the parity of the woman would have significant influence on the fertility of HIV infected women after knowing about their HIV status.

Reduction in sexual activity and increase in use of condoms (which is advised to all HIV infected couples to avoid cross infection when both partners are HIV infected and to prevent HIV transmission when any one of the partners is infected with HIV) seem to be the most important proximate determinants of fertility decline among HIV infected women. In our study, information about sexual frequency and contraceptive use was collected from women who were married and fecund at the time of interview $(N=229)$. Of these women, $17 \%(N=40)$ were completely abstaining from sex (no sexual intercourse for more than a year). Of the women who had sex in the year prior to the interview, the average monthly frequency of sexual intercourse was four. Of the married and fecund women, $90 \%$ were using condom as the only source of contraception and the majority did not feel the need to use any other method of contraception as the frequency of sexual intercourse was significantly low.

The HIV epidemic in India is concentrated in high risk groups and has wide geographic heterogeneity with an estimated adult HIV prevalence in the country in 2011 of $0.27 \%$ [24]. However, $53 \%$ of the estimated 2.09 million HIV infected people are in the four southern states of the country (Andhra Pradesh, Karnataka, Maharashtra, and Tamil Nadu) [24]. It is interesting to note that these four states with high HIV prevalence also have lower total fertility rates which are estimated to be at or below replacement level (on average 2 children per woman) [30]. With the increase in HIV testing among pregnant women, a higher proportion of women are expected to know about their HIV status early in their reproductive career. This awareness about their HIV positive status could lead to a decline in fertility among HIV infected women.

Based on the findings of our study of significant lower pregnancy rates after knowledge about HIV status, it is likely that the current estimations of HIV infected pregnant women are too high. Since the beginning of the HIV epidemic, surveillance of HIV infection in antenatal clinics (ANC) has been the main system of monitoring the epidemic [5] in most countries including India because of easy accessibility of pregnant women in ANCs [31]. For estimating the number of HIV infected pregnant women in the country, the data on HIV prevalence are fed to the Spectrum package. Due to lack of data on fertility of HIV infected women in India, default assumptions in the package are used for estimation which assumes 30\% lower fertility among HIV infected women compared to uninfected women [32]. However, based on the findings of this and our earlier study, which did not find any significant biological difference in pregnancy rates of HIV infected and HIV uninfected women in India [8], it seems very likely that the lower fertility among HIV infected Indian women is primarily due to the behavioural effect of
HIV. Therefore, it appears that a more accurate estimation of the number of HIV infected pregnant women in the country can be made by considering the differential fertility rate before and after knowing about HIV status. Currently about $40 \%$ of HIV infected women in India are not aware of their HIV positive status [24] and will most likely not have lower fertility as compared to noninfected women. More importantly, however, the fertility levels of $60 \%$ HIV infected women who are aware of their HIV status could be lower than the assumed fertility levels. Also, as the proportion of pregnant women knowing about their HIV positive status early in their reproductive career is increasing over time, the fertility levels among HIV infected women could decline to even much lower levels than currently assumed.

In the context of this study we refer to biological effect as the effect of HIV before the woman is aware of her HIV positive status and behavioural effect as the effect after the woman is aware about her HIV positive status. Previous research from India on the biological effect of HIV fertility, that is, the effect of HIV on the occurrence of pregnancies among HIV infected women who were not aware about their HIV status [8], found no significant difference in the pregnancy rates of HIV infected women compared to HIV uninfected women. Therefore reduction in fertility due to $\mathrm{HIV}$ appears to be mainly related to changes in reproductive decision making of the couples. It should be noted, however, that also after the woman is aware about her HIV positive status other biological or clinical processes such as disease progression (low CD4 counts, high viral loads) or treatment with ART might also have some unmeasured impact.

This study-similar to most other clinic based studieshas certain limitations. Because the women attending the HIV clinic were enrolled and followed up in time retrospectively there is the possibility of survival bias in the sample. That is, women who were no longer engaged in care (either died due to HIV or other causes or lost to follow-up) were not included in the study. A recent systematic review and meta-analysis (2015) on the effect of pregnancies on HIV disease progression, however, did not find enough evidence to conclude that pregnancy has an effect on HIV disease progression among HIV infected women [33]. Therefore we can assume that the primary outcome of our study, that is, occurrence of pregnancies, did not contribute towards mortality and loss to follow-up of women in care and hence the results of our study are not expected to be significantly affected by survival bias especially when we standardized pregnancy rates by age and parity.

Using retrospectively collected self-reported data on pregnancies, reporting bias can occur because women might be prone to underreport pregnancies that did not result in live births. Again, due to the extensive training of the interviewers, the use of the calendar method [34], and conversational interview techniques, we believe that this bias is reduced to the minimal. Analysis of reported pregnancy outcomes such as induced abortions ( $50 \%$ of the pregnancies conceived after diagnosis of HIV were voluntarily terminated) also does not indicate underreporting as the rates are high and comparable with other published studies [28, 35]. Because of the commencement of the private sector PMTCT Program by Prayas, 
an increasing number of HIV infected pregnant women were referred to the Prayas Clinic for PMTCT services from all over the state of Maharashtra. These referrals could also lead to bias in the sample due to overrepresentation of pregnant women. However, restriction of observation period up to 2009 and standardizing pregnancy rates with age and parity might have reduced the effect of this bias.

\section{Conclusion}

Despite of the methodological limitations, our study contributes significantly to the understanding of the behavioural effect of HIV on pregnancy rates by separating its influence from the biological effect of HIV. While this study documents the lower pregnancy rates after the couples' HIV status is known, it was not intended to explain the mechanisms through which this behavioural effect is exerted. Further studies among Indian women to understand the socioeconomic and cultural factors behind the lower fertility after knowledge about HIV status are required.

The finding of lower pregnancy rate after knowledge about HIV and lower likelihood of HIV infected women to progress to higher parity would be particularly relevant for informing fertility assumptions of HIV infected Indian women for the estimation of number of HIV infected pregnant women in the country. It seems essential to understand and ensure that the lower fertility after knowing about the HIV positive status is a result of couples' informed decision making and is not resulting from lack of information on PMTCT, fear of MTCT, and stigmatization and discrimination from health care providers. There is a need to ensure that HIV infected women have access to adequate services to achieve their desired reproductive goals.

\section{Conflict of Interests}

The authors declare that there is no conflict of interests regarding the publication of this paper.

\section{Acknowledgments}

The authors would like to thank all the HIV infected women who participated in the study and shared their personal and often painful stories with them and Ms. Neha Vaidya and Dr. Trupti Darak of Prayas Health Group, Pune, for their sensitive and sincere efforts of talking to HIV infected women for data collection and their help in data entry and validation. This study received financial support from the Population Research Centre, Faculty of Spatial Sciences, University of Groningen and Eric Bleumink Foundation, University of Groningen, Netherlands.

\section{References}

[1] UNAIDS, "Progress report on the global plan: towards the elimination of new HIV infections among children by 2015 and keeping their mothers alive," UNAIDS JC2509/2/E, 2013.
[2] UNAIDS, Down to the Details: Fast-Tracking the Response to End the AIDS Epidemic by 2030, UNAIDS, 2014.

[3] A. Kaida, I. Andia, M. Maier et al., "The potential impact of antiretroviral therapy on fertility in sub-Saharan Africa," Current HIV/AIDS Reports, vol. 3, no. 4, pp. 187-194, 2006.

[4] M. Maier, I. Andia, N. Emenyonu et al., "Antiretroviral therapy is associated with increased fertility desire, but not pregnancy or live birth, among HIV+ women in an early HIV treatment program in rural Uganda," AIDS \& Behavior, vol. 13, supplement 1, pp. S28-S37, 2009.

[5] W.-J. Chen and N. Walker, "Fertility of HIV-infected women: insights from demographic and Health Surveys.", Sexually Transmitted Infections, vol. 86, supplement 2, pp. ii22-ii27, 2010.

[6] J. J. C. Lewis, C. Ronsmans, A. Ezeh, and S. Gregson, "The population impact of HIV on fertility in Sub-Saharan Africa," AIDS, vol. 18, supplement 2, pp. S35-S43, 2004.

[7] A. Ross, L. van der Paal, R. Lubega, B. N. Mayanja, L. A. Shafer, and J. Whitworth, "HIV-1 disease progression and fertility: the incidence of recognized pregnancy and pregnancy outcome in Uganda," AIDS, vol. 18, no. 5, pp. 799-804, 2004.

[8] S. Darak, F. Janssen, and I. Hutter, "Fertility among HIVinfected Indian women: the biological effect and its implications," Journal of Biosocial Science, vol. 43, no. 1, pp. 19-29, 2011.

[9] B. Zaba and S. Gregson, "Measuring the impact of HIV on fertility in Africa," AIDS, vol. 12, supplement 1, pp. S41-S50, 1998.

[10] M. A. Magadi and A. O. Agwanda, "Investigating the association between HIV/AIDS and recent fertility patterns in Kenya," Social Science and Medicine, vol. 71, no. 2, pp. 335-344, 2010.

[11] J. M. Blair, D. L. Hanson, J. L. Jones, and M. S. Dworkin, “Trends in pregnancy rates among women with human immunodeficiency virus," Obstetrics \& Gynecology, vol. 103, no. 4, pp. 663668, 2004.

[12] M. Sharma, R. R. Singh, P. Laishram et al., "Access, adherence, quality and impact of ARV provision to current and exinjecting drug users in Manipur (India): an initial assessment," International Journal of Drug Policy, vol. 18, no. 4, pp. 319-325, 2007.

[13] J. Homsy, R. Bunnell, D. Moore et al., "Reproductive intentions and outcomes among women on antiretroviral therapy in rural Uganda: a prospective cohort study," PLoS ONE, vol. 4, no. 1, Article ID e4149, 2009.

[14] B. S. Linas, H. Minkoff, M. H. Cohen et al., "Relative time to pregnancy among HIV-infected and uninfected women in the Women's Interagency HIV study, 2002-2009," AIDS, vol. 25, no. 5, pp. 707-711, 2011.

[15] A. Kaida, F. Laher, S. A. Strathdee et al., "Childbearing intentions of HIV-positive women of reproductive age in Soweto, South Africa: the influence of expanding access to haart in an hiv hyperendemic setting," American Journal of Public Health, vol. 101, no. 2, pp. 350-358, 2011.

[16] S. R. Schwartz, H. Rees, S. Mehta, W. D. F. Venter, T. E. Taha, and V. Black, "High incidence of unplanned pregnancy after antiretroviral therapy initiation: findings from a prospective cohort study in south africa," PLOS ONE, vol. 7, no. 4, Article ID e36039, 2012.

[17] S. R. Schwartz, J. Bassett, I. Sanne, R. Phofa, N. Yende, and A. Van Rie, "Implementation of a safer conception service for HIVaffected couples in South Africa," AIDS, vol. 28, supplement 3, pp. S277-S285, 2014. 
[18] A. Kaida, L. T. Matthews, S. Kanters et al., "Incidence and predictors of pregnancy among a cohort of HIV-positive women initiating antiretroviral therapy in Mbarara, Uganda," PLoS ONE, vol. 8, no. 5, Article ID e63411, 2013.

[19] A. Kaida, I. Andia, M. Maier et al., "The potential impact of antiretroviral therapy on fertility in Sub-Saharan Africa," Current HIV/AIDS Reports, vol. 3, no. 4, pp. 187-194, 2006.

[20] J. Bongaarts and R. G. Potter, Fertility, Biology and Behavior: An Analysis of Proximate Determinants, Academic Press, New York, NY, USA, 1983.

[21] L. M. Carpenter, J. S. Nakiyingi, A. Ruberantwari, S. S. Malamba, A. Kamali, and J. A. G. Whitworth, "Estimates of the impact of HIV infection on fertility in a rural Ugandan population cohort," Health Transition Review, vol. 7, supplement 2, pp. 113-126, 1997.

[22] S.-C. Hunter, R. Isingo, J. T. Boerma, M. Urassa, G. M. P. Mwaluko, and B. Zaba, "The association between HIV and fertility in a cohort study in rural Tanzania," Journal of Biosocial Science, vol. 35, no. 2, pp. 189-199, 2003.

[23] S. E. Huntington, C. Thorne, L. K. Bansi et al., "Predictors of pregnancy and changes in pregnancy incidence among HIVpositive women accessing HIV clinical care," AIDS, vol. 27, no. 1, pp. 95-103, 2013.

[24] NACO, Annual Report-2012-2013, 2013.

[25] A. G. Dean, K. M. Sullivan, and M. M. Soe, OpenEpi:Open source epidemiologic statistics for public health, version 2.3.1, 2011.

[26] P. Boyle and D. M. Parkin, "Statistical methods for registries," in Cancer Registration: Principles and Methods, O. M. Jensen, D. M. Parkin, R. MacLennan, C. S. Muir, and R. G. Skeet, Eds., pp. 126158, International Agency for Research on Cancer, Lyon, France, 1991.

[27] S. Kanniappan, M. J. Jeyapaul, and S. Kalyanwala, "Desire for motherhood: exploring HIV-positive women's desires, intentions and decision-making in attaining motherhood," AIDS Care: Psychological and Socio-medical Aspects of AIDS/HIV, vol. 20, no. 6, pp. 625-630, 2008.

[28] A. Ammassari, P. Cicconi, N. Ladisa et al., "Induced first abortion rates before and after HIV diagnosis: results of an Italian self-administered questionnaire survey carried out in 585 women living with HIV," HIV Medicine, vol. 14, no. 1, pp. 31-39, 2013.

[29] Y. Berhan and A. Berhan, "Meta-analyses of fertility desires of people living with HIV," BMC Public Health, vol. 13, no. 1, article 409, 2013.

[30] IIPS Macro-International, National Family Health Survey (NFHS-3) 2005-2006, IIPS Macro-International, Mumbai, India, 2007.

[31] NACO, “Annual report 2009-2010,” Tech. Rep., NACO, 2010.

[32] NACO, "India HIV estimates," Tech. Rep., Netherlands Airport Consultants, The Hague, The Netherlands, 2010.

[33] C. Calvert and C. Ronsmans, "Pregnancy and HIV disease progression: a systematic review and meta-analysis," Tropical Medicine \& International Health, vol. 20, no. 2, pp. 122-145, 2015.

[34] W. G. Axinn, L. D. Pearce, and D. Ghimire, "Innovations in life history calendar applications," Social Science Research, vol. 28, no. 3, pp. 243-264, 1999.

[35] N. Abdala, T. Kershaw, T. V. Krasnoselskikh, and A. P. Kozlov, "Contraception use and unplanned pregnancies among injection drug-using women in St Petersburg, Russia," Journal of Family Planning and Reproductive Health Care, vol. 37, no. 3, pp. 158-164, 2011. 

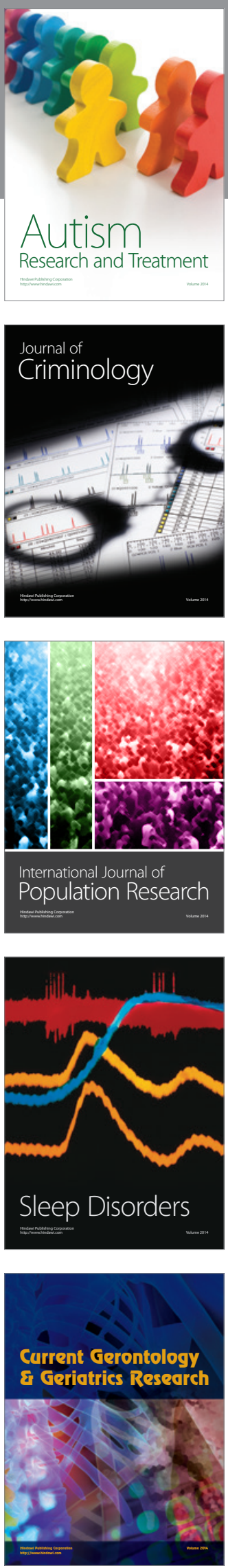
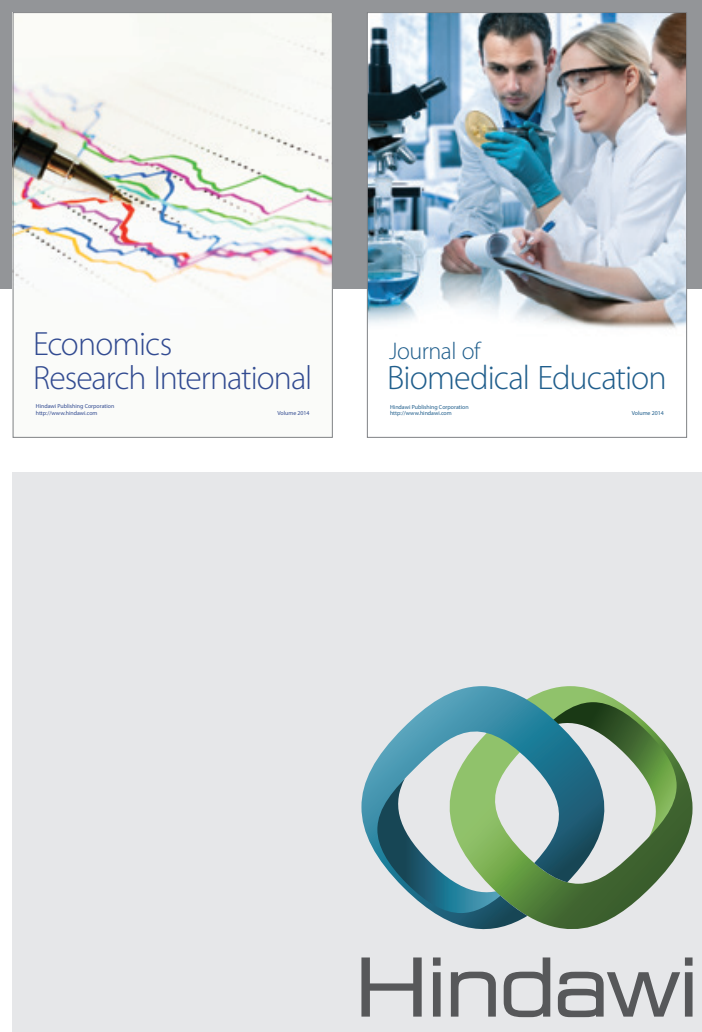

Submit your manuscripts at

http://www.hindawi.com
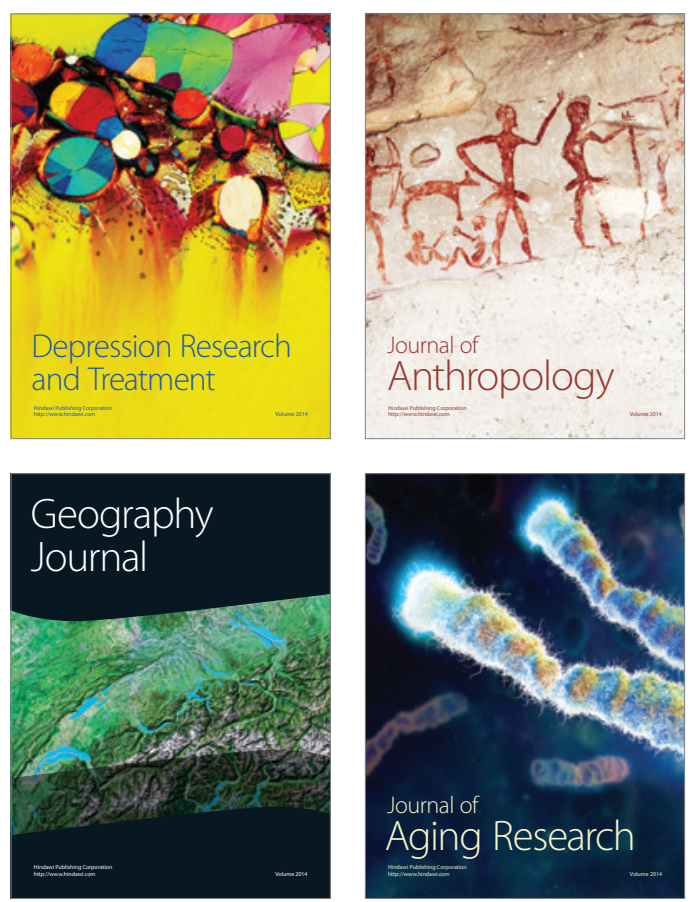
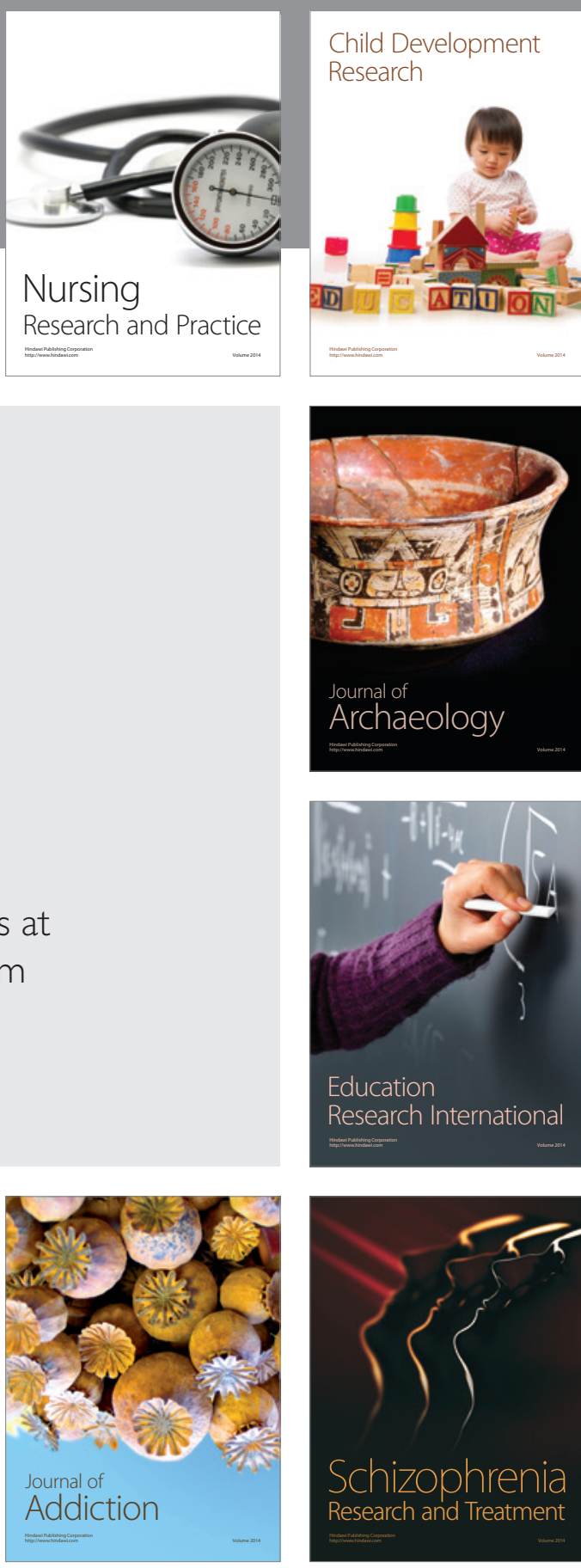

(D)
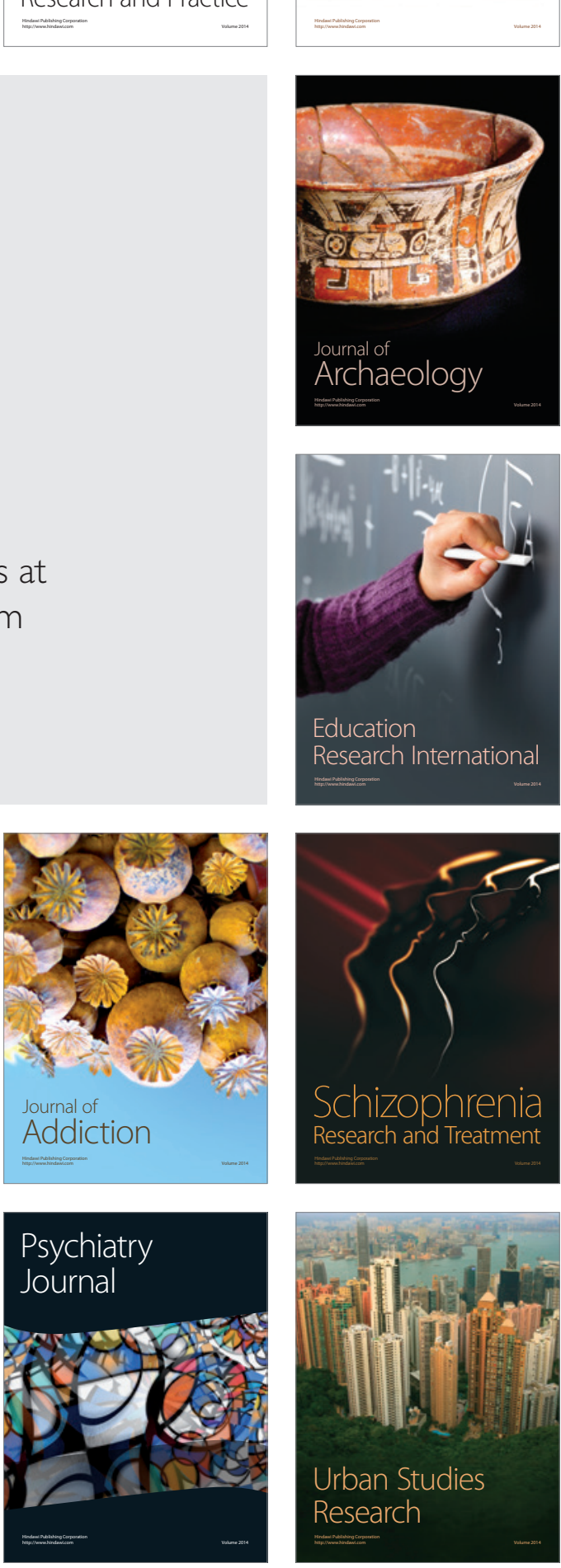